\title{
An exemplary developing astronomy movement in Nepal
}

\author{
Sudeep Neupane \\ Astronomical Society (NASO), Astrophysics and Cosmology Research Group, TU
}

\begin{abstract}
Astronomy and space science education had been given least importance by Nepalese government in the past. The modern astronomy movement is believed to have started when an official observation programme of Haley's comet was organized by Royal Nepal Academy of Science and Technology (RONAST) in 1986. Following the huge pressure from the scientific community, the Nepal government (Kingdom of Nepal at that time) established B.P. Koirala Memorial Planetarium, Observatory and Science Museum Development Board in 1992. Initiatives of the project started with observatory set up and the development of astrophysics syllabus for university students. Astrophysics is included as an elective paper in the Physics masters course. The lead astrophysicist of Nepal Dr. Binil Aryal is running a research group in Tribhuvan University since 2005 which has a significant number of international publications. The developing government initiatives and achievements will be discussed.

In 2007, a group of astronomy enthusiastic students along with amateurs working independently in past established Nepal Astronomical Society (NASO), which surprisingly increased the amateur activities and inspired other amateur groups to revive. During IYA 2009, more than 80 outreach and observation events were organized solely by NASO. NASO was able to collaborate with many international programmes and projects like GHOU/GTTP, EurAstro, AWB, UNAWE, SGAC, Star Peace, TWAN etc during and beyond IYA2009. Currently Nepal is recognized as the most eventful country of outreach and astronomy education among the amateur community. The success story of the astronomy movement and the local difficulties while organizing the events will be explained.
\end{abstract}

Keywords. Outreach, NASO, NAST, Planetarium, Observatory, GHOU, GTTP, UNAWE 